\title{
Espelho falso: a paródia na formação do teatro brasileiro
}

False mirror: parody in the formation of Brazilian theatre

Marta Metzler

Marta Metzler

Doutora pelo PPGAC da UNIRIO

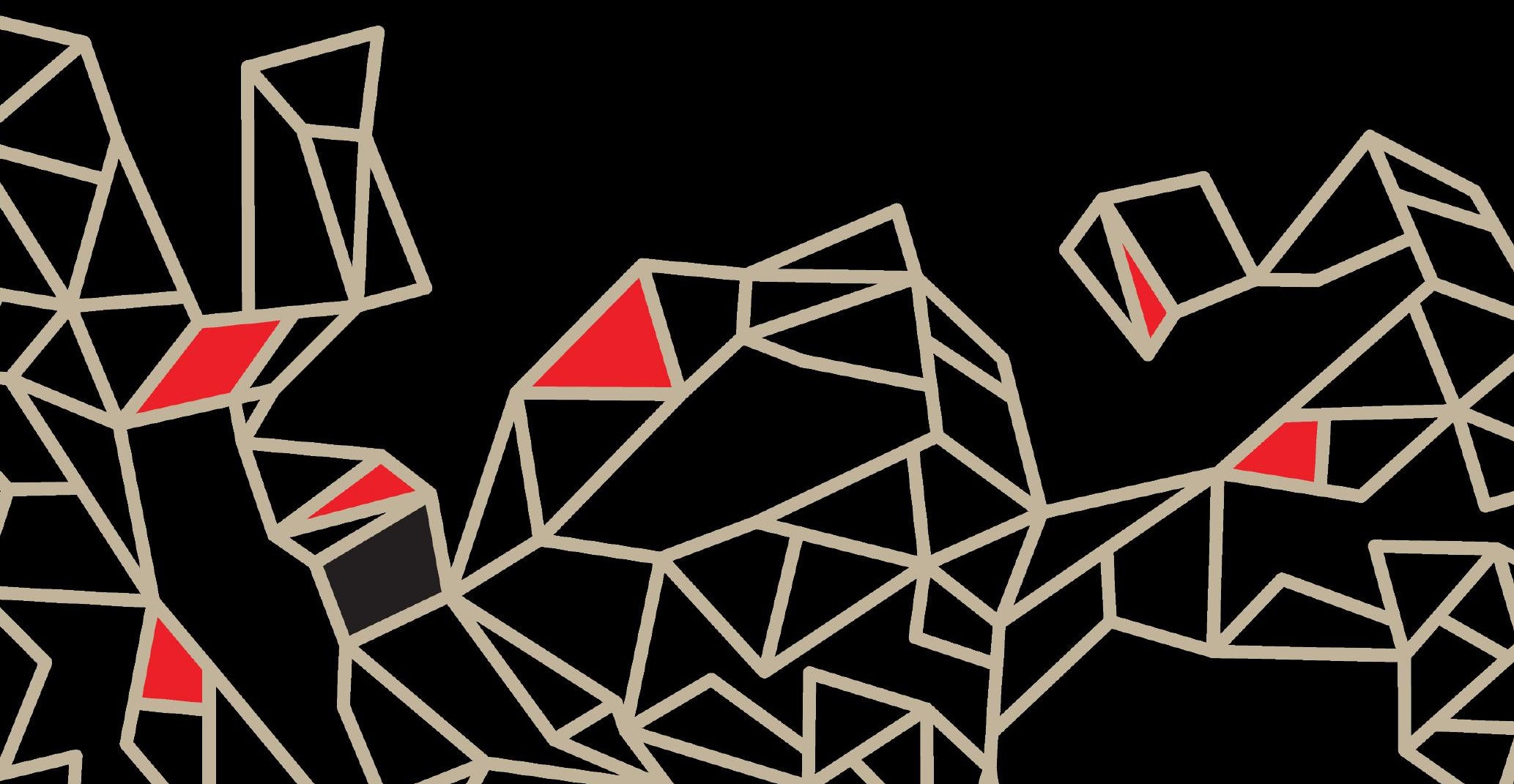




\section{Resumo}

Este trabalho articula-se em torno da relação entre as formas paródicas e a atividade teatral desenvolvida no Brasil, com a ideia de que a práxis parodística está diretamente implicada no processo de formação dos autores e na própria construção da noção de teatro brasileiro. A paródia é uma arte que se manifesta por polifonia, entrecruzando vozes, tempos, lugares, descentrando valores e sentidos artístico-culturais. Considerando que, no caso brasileiro, formas marginais como a paródia ocupam o centro da formação teatral, o olhar se situa nos deslimites em que se entrelaçam origem e destino, centro e periferia. Objetiva-se realizar um estudo crítico, seguindo uma perspectiva histórica, trabalhando com investigação, registro e análise de material dramatúrgico, bibliográfico e jornalístico, em interconexão com o exame teórico-conceitual fundamentado em estudos contemporâneos da paródia, da história do teatro brasileiro e da cultura.

Palavras-chave: paródia, história do teatro brasileiro, cultura.

\section{Abstract}

This study articulates the relationship between parodic forms and theatrical activity developed in Brazil, with the idea that the parodic praxis is directly related to the formation of authors and the construction of the Brazilian theater. Parody is an art that manifests itself through polyphony, crisscrossing voices, times, places, decentralizing values and artistic and cultural meanings. Considering that in the Brazilian case, marginal forms such as parody are in the center of theatrical formation, the perspective is located at the unlimits in which origin/ destination and center/periphery are intertwined. The objective here was to carry out a critical study through an historical perspective with research, register and analysis of dramaturgical, bibliographic and journalistic material in interconnection with a theoretical and conceptual examination based on contemporary studies of parody, the history of the Brazilian theater and culture.

Keywords: parody, history of the Brazilian theatre, culture. 
$\mathrm{O}$ vidro nos espreita. Se entre as quatro

Paredes do quarto existe um espelho, Já não estou sozinho. Há outro. Há o reflexo Que arma na aurora um sigiloso teatro. [...]

Cláudio, rei de uma tarde, rei sonhado, Não sentiu que era um sonho até o dia

Em que um ator mimou sua felonia Com arte silenciosa, em um tablado.

(Jorge Luis Borges, Os espelhos)

A paródia é uma prática que se consolida nas artes cênico-dramatúrgicas brasileiras, entre os séculos XIX e XX, assumindo papel formador da atividade teatral no Brasil.

Se, por um lado, temos o chamado "teatro sério" empenhado em se alinhar às práticas cênicas europeias, importando modelos a serem reproduzidos, por outro, temos o teatro cômico reprocessando imediatamente tais modelos por meio da paródia. Ambos os processos são formadores do teatro brasileiro e, em alguma medida, ambos são devoradores da cultura europeia sob uma perspectiva antropofágica. Neste trabalho, no entanto, o olhar se deterá sobre o movimento realizado pela paródia.

No repertório daquele que é considerado o primeiro ator brasileiro, João Caetano, figurava a peça Otelo, versão de Jean-François Ducis, escrita em prosa a partir de tradução francesa da tragédia de Shakespeare, que, por sua vez, foi inspirada no conto $A$ infidelidade de maridos e esposas, de Giovanni Battista Giraldi, autor italiano também conhecido como Giraldi Cinthio ${ }^{1}$. A montagem de João Caetano, que contou com tradução de Gonçalves de Magalhães e teve 26 representações entre 1837 e 1860, deu ensejo a duas paródias: Os ciúmes de um pedestre, de Martins Pena, apresentada em 1846, e O novo Otelo, de Joaquim Manuel de Macedo, de 1863. Há ainda O caboclo, de Aluísio Azevedo e Emílio Rouède, que subiu ao palco pela primeira vez em 1886 e faz outro tipo de aproveitamento do modelo original, em uma composição metateatral. São textos de natureza muito diversa, mas que possuem, como traço comum, o gesto de apropriação e recriação.

1. O conto faz parte do livro Hecathommithi, composto de dez grupos de dez contos cada. Cf. TAVARES, 2007, p. 16-17. 
À investigação da prática parodística no teatro brasileiro interessa particularmente, como referência, Hutcheon (1985), pois a autora refuta a ideia de que a paródia, em obras não literárias, esteja limitada a ser mera transferência da prática da literatura. Isso concerne a este estudo, que lida com peças escritas com base no referente espetacular, e não textual.

A memória do referente não se descola da paródia; permanece em fundo, ou, antes, em paralelo ${ }^{2}$, permitindo que a paródia funcione como tal. Sua recepção, para acontecer de forma ampla, depende do reconhecimento por parte do espectador, que, de modo ativo, estabelece as associações entre a paródia e seu referente. Como um mosaico de textos, contém o modelo (em memória) e seu reflexo (divergente). É assim que os espetáculos paródicos podem ganhar sentidos com seu público, na mesma medida em que se guardam na lembrança aqueles que foram alvos de paródia. É a modalidade de espetáculo-paródia, que, a princípio, caracteriza a prática parodística no teatro cômico brasileiro, desde seus inícios com o emblemático Orfeu na roça, do ator Vasques.

Com a saga mitológica de Orfeu dá-se um processo um pouco diferente, pois chega ao Brasil já parodiada. Jacques Offenbach fazia imenso sucesso em Paris com a ópera cômica Orphée aux Enfers ${ }^{3}$, paródia da ópera Orfeu e Eurídice, de Christoph Willibald Gluck com libreto de Ranieri de' Calzabigi. Sete anos depois de estrear na capital francesa, a peça de Offenbach aportou no Rio de Janeiro em 1865, em montagem que ocupou o teatro Alcazar Lyrique por dois anos, com mais de trezentas récitas em francês até 1867, segundo o Jornal do Commercio ${ }^{4}$. Em 1868 foi a vez de Francisco Corrêa Vasques, ator cômico, estrear Orfeu na roça, de sua autoria, uma paródia da paródia, que obteve enorme sucesso ao transformar as personagens de Offenbach em figuras do universo rural brasileiro.

"Muito bem! Vamos refazer a mitologia!"5, diz Júpiter em Orphée aux Enfers. A ópera de Offenbach-Crémieux parodia a cultura clássica, rebaixando

2. Conforme o sentido etimológico da palavra "paródia", isto é, "canto paralelo", como sinaliza Haroldo de Campos (1967, p. 16).

3. Música de Jacques Offenbach, libreto de Hector Crémieux.

4. Ver Pinto \& Rabetti (2014).

5. As traduções dos trechos da ópera são da autora. 
moralmente as figuras do panteão romano, com vistas a um ataque mordaz e humorado à sociedade francesa. Apropria-se das personagens mitológicas e tira partido da história que reconstrói para criticar as autoridades políticas, personalizadas nos membros do núcleo familiar de Júpiter. A hipocrisia dos governantes se explicita na fala do deus soberano, diante de uma rebelião que questiona sua autoridade: "Eu o disse pela honra da mitologia! Pelo amor de deus! Meus filhos, os fracos mortais estão de olho em nós! Salvemos as aparências pelo menos! Salvemos as aparências!" (OFFENBACH, CRÉMIEUX, 1858).

Vasques, por seu turno, desloca o eixo do plano divino para o terreno. Ao fazê-lo, coloca no centro o Brasil - ou uma percepção de Brasil - ainda que configurada em uma centralidade de desvãos, firmada por um gênero das margens. $O$ ator-autor segue ponto por ponto a estrutura do seu referente, fazendo, no entanto, uma adequação de cunho moral: transforma Júpiter no autoritário Mamede, que, na condição de juiz de paz, vê-se onipotente; manda e desmanda tal como uma divindade. Mas, enquanto Júpiter, ao final, entrega Eurídice a Baco, Mamede envia Brígida (personagem correspondente de Eurídice em Orfeu na roça) para o convento - vai ser freira.

Segundo Rubens José Souza Brito, o sucesso de Orfeu na roça foi ainda maior que o de Orphée aux Enfers ${ }^{6}$.

A cidade do Rio de Janeiro era parte do roteiro das turnês de companhias teatrais estrangeiras, e muitas das peças apresentadas na então capital imperial serviram de fonte para as paródias brasileiras: La Grande-Duchesse de Gérolstein torna-se A Baronesa de Caiapó; Barbe-Bleue vira Barba de Milho e também Traga-Moças; Gavaud, Minard \& cie. naturaliza-se como Vaz Teles \& cia. ${ }^{7}$. Essa concorrência irresistível, ao invés de arrefecer, fortalece a ambos.

É legítimo pensar que, inicialmente, a paródia cumpre a função de estudo e aprendizado no ofício dos nossos autores. Para Linda Hutcheon (1985), as formas paródicas

6. Ver "O teatro cômico e musicado: operetas, mágicas, revistas de ano e burletas" (FARIA, 2012, p. 219-233).

7. La Grande-Duchesse de Gérolstein, música de Jacques Offenbach, libreto de Henri MeiIhac e Ludovic Halévy; A Baronesa de Caiapó, de Caetano Filgueiras, Manoel Joaquim Ferreira Guimarães e Antônio Maria Barroso; Barbe-Bleue, música de Offenbach, libreto de Meilhac e Halévy; Barba de Milho, de Augusto de Castro; Traga-Moças, de Joaquim Serra; Gavaud, Minard \& cie., comédia de Edmond Gondinet; Vaz Teles \& cia., de Augusto de Castro. 
[...] assinalam menos um reconhecimento da "insuficiência das formas definíveis" dos seus precursores [...] que o seu próprio desejo de pôr a "refuncionar" essas formas, de acordo com as suas próprias necessidades. Este método mais positivo de tratar o passado recorda, em muitos aspectos, as atitudes clássicas e renascentistas perante o patrimônio cultural. Para escritores como Ben Jonson, era evidente que a imitação das obras anteriores era considerada parte do labor de escrever poesia. (p. 15)

A trajetória de Arthur Azevedo ilustra bem tal hipótese. A peça de estreia profissional do autor no Rio de Janeiro ${ }^{8}$, A filha de Maria Angu, de 1876, é uma paródia da ópera cômica La Fille de Marie Angot $^{9}$. A ela seguem-se $A$ casadinha de Fresco, paródia de La petite mariée ${ }^{10}$, encenada em 1876, e Abel Helena, paródia de La Belle Hélène ${ }^{11}$, levada à cena em 1877.

La Belle Hélène, de Offenbach, Meilhac e Halévy, parodia o mito de Helena de Troia. Arthur Azevedo também segue ponto por ponto a intriga da trama de referência e, do mesmo modo que Vasques, retira o enredo do universo mitológico e o transpõe para um cenário brasileiro, afinado com um projeto de afirmação e valorização da nacionalidade. Calchas, o áugure, torna-se Cascais, o padre; a festa de Adonis, torna-se uma festa literária depois da missa das dez, que, assim como a primeira, dará um prêmio a quem vencer três provas de inteligência. Arthur Azevedo também fará ajustes ao sentimento local. Na paródia francesa, Helena é casada com Menelau, mas deverá ser entregue a Páris a quem foi prometida por Vênus. Menelau, mesmo a contragosto será instado a ceder, já que sua resistência levara a deusa a lançar sobre a Grécia uma epidemia de infidelidade conjugal. Em Azevedo, porém, Menelau é transformado em Nicolau, padrinho de Helena, que é solteira, e o único obstáculo desta à permissão para se casar com Abel (correspondente a Páris) é o fato de ele ser um professor público pobre, ao passo que o padrinho almeja casar Helena com um homem rico.

Em Abel Helena, Azevedo defende, de quebra, o próprio gênero da paródia. Na ópera francesa, o prêmio do concurso será receber das mãos da

8. O maranhense Arthur Azevedo já havia escrito peças curtas, entre elas Amor por anexins, que encenou ainda em São Luís, antes de fixar-se no Rio de Janeiro (a partir de 1873, aos 18 anos de idade), onde construiu sua carreira.

9. Música de Charles Lecocq, libreto de Paul Siraudin, Nicolaïe Clairville e Victor Koning.

10. Música de Lecocq, libreto de Eugène Leterrier e Albert Vanloo.

11. Música de Offenbach, libreto de Meilhac e Halévy. 
rainha (Helena) uma guirlanda de flores de pinho (Agamemnon pensara, inicialmente, em premiar com uma coroa de ouro, mas repensou: para pessoas de esp írito, pinho está bom demais!). Já na paródia de Azevedo, o concurso oferecerá ao vencedor um exemplar impresso de $A$ filha de Maria Angu, tornando-o, debochadamente, o centro da disputa:

PANTALEÃO - [...] Quem glosar o mote, responder à pergunta e decifrar a charada, receberá das mãos da Senhora Dona Helena, este livro... (entrega a Helena um exemplar impresso de A filha de Maria Angu.)

PEDRINHO - E que livro é esse? Dá licença? (Toma o livro e lê o título.) A filha de Maria Angu.

ALFERES ANDRADE - Ora via! Uma paródia! Uma paródia!... NICOLAU - E o que tem que seja uma paródia?

ALFERES ANDRADE - Vi-a representar... É a maior bagaceira... (Com energia, puxando pela espada.) E não me digam que não é!...

NICOLAU - Quem foi que disse, Seu Alferes? Guarde a durindana, homem!

ALFERES ANDRADE - É assim que o Senhor Pantaleão de los Rios quer fazer literatos: dando-Ihes de presente $A$ filha de Maria Angu! (AZEVEDO, 1877, p. 10-11)

Logo adiante, o Alferes Andrade arremata: "Eu disse paródia! E ele é! O que é que tem graça? Paródia! (Murmúrios.)".

Corroborando a hipótese, Rubens José Souza Brito aponta:

Encorajado pelos sucessos obtidos no palco e consciente de que podia lançar mão do próprio talento para escrever os enredos das operetas, já em 1877 Artur Azevedo arrisca-se como coautor de Nova viagem à Lua, dividindo a coautoria com Frederico Severo. Nessa opereta, que estreia no Teatro Fênix Dramática, ele aproveita a música de Lecocq, mas pede a Henrique Mesquita que componha um jongo para o primeiro ato e uma barcarola para o segundo. Com Os noivos e A princesa dos cajueiros, encenadas em 1880, também no Fênix, Artur Azevedo nacionaliza por completo a opereta, tendo como parceiro o compositor português Francisco de Sá Noronha. (FARIA, 2012, p. 220-222)

A prática da paródia era tão corriqueira que talvez fosse esperado que espetáculos bem sucedidos fossem imediatamente parodiados. Ou, quem sabe, ter uma paródia indicasse o quão notável era o espetáculo. É o que 
parece indicar o procedimento do Cyclo Theatral Brasileiro, empresa que promoveu o Teatro da Natureza no Rio de Janeiro, em 1916:

[...] o Cyclo Theatral Brasileiro organiza, paralelamente ao Teatro da Natureza, uma companhia de operetas, revistas e féeries que, instalada no Palace-Theatro, estreia no dia 15 de janeiro e se dissolve em março. Ao longo desses dois meses, o Cyclo paga por um espaço no jornal para anunciar, num mesmo quadro, todas as peças da empresa - tanto as do Teatro da Natureza, quanto as do Palace-Theatro. No dia 15 de fevereiro, a página 14 do Correio da Manhã exibe o que há de mais curioso: postos lado a lado, na publicidade do Cyclo, estão os anúncios das peças Antigona, do Teatro da Natureza, e De Pernas Pr'o Ar, cujo grande chamariz é a epígrafe Crítica ao Teatro da Natureza! Algumas revistas então em cartaz no Rio de Janeiro parodiam o Teatro da Natureza, e uma delas é produção do próprio Cyclo Theatral Brasileiro. (METZLER, 2006, p. 80)

Os espetáculos de revista, de fato, continham, frequentemente, quadros paródicos em que se via, por exemplo, Dercy Gonçalves representando Julieta, ou Oscarito no papel de Cleópatra' ${ }^{12}$. Silêncio, Rio!, revista de Freire Jr. de 1941, homenageava a própria estrela da companhia, Alda Garrido: "Numa cortina irresistível, cinco estrelas célebres eram imitadas: Araci Cortes por Pedro Dias, Dulcina de Morais por Humberto Freddy, Bibi Ferreira por Paulo Brás, Beatriz Costa pelo saxofonista e cantor Ratinho e a própria Alda Garrido pelo cantor e compositor Jararaca" (PAIVA, 1991, p. 475). A atriz Alda Garrido, por sua vez, já em 1957, depois de migrar para a comédia, escreverá e montará Chuvisco, espetáculo-paródia da peça Chuva, carro-chefe da carreira de Dulcina de Morais ${ }^{13}$.

\section{Reflexos divergentes}

Assim como nenhum de nós está fora ou além da geografia, da mesma forma nenhum de nós está totalmente ausente da luta pela geografia. Essa luta é complexa e interessante porque não se restringe a soldados e canhões, abrangendo também ideias, formas, imagens e representações.

(Edward W. Said, Cultura e imperialismo)

12. Ver Veneziano (1991, p. 103).

13. Ver Metzler (2011, p. 172-189). 
Considerando que nossos primeiros dramaturgos não contavam com uma escola, fosse de arte teatral, de modo geral, ou de escrita dramatúrgica, especificamente, é possível pensar a formação dos autores do teatro brasileiro inspirando-se, por analogia, no pensamento de Haroldo de Campos para os autores da nossa literatura, como se verá a seguir.

Para Haroldo de Campos,

[...] o Barroco, para nós, é a não-origem, porque é a não-infância. Nossas literaturas, emergindo com o Barroco, não tiveram infância (infans: o que não fala). Nunca foram afásicas. Já nasceram adultas (como certos heróis mitológicos) e falando um código universal extremamente elaborado: o código retórico barroco [...]. Articular-se como diferença em relação a esta panóplia de universalia, eis o nosso "nascer" como literatura: uma sorte de partenogênese sem ovo ontológico (vale dizer: a diferença como origem ou o ovo de Colombo...) (CAMPOS, 1983, p. 113)

Quanto ao teatro, embora se manifeste no Brasil desde o século XVI, com a chegada dos jesuítas, retira-se das formas utilitárias de catequese e do âmbito das festas cívicas e religiosas somente na primeira metade do século XIX, depois da instalação da corte portuguesa no país. Para o nosso estudo interessa considerar esse teatro profissional estabelecido como fato social, com continuidade de palco. De todo modo, assim como a literatura, o teatro no Brasil "já nasce adulto". É pela devoração da cultura europeia que nossos autores apreendem o exercício de escrita, que se constrói não por derivação direta, mas por uma "torção e contorção de um discurso que nos pudesse desensimesmar do mesmo" (CAMPOS, 1983, p. 116). Estabelece-se um jogo especular - nosso des-ensimesmamento, nosso êxtase -, em que a imagem é gerada por desvios que distorcem o modelo original, que ampliam, reduzem, re/velam o mesmo tornado outro. No processo de formação cultural brasileiro, o gesto paródico produz um deslocamento dobrado, ou, talvez, não apenas duplo. O encontro forçado, violento e conflituoso de várias culturas heterogêneas produziu, no Brasil, um sincretismo que mescla e confunde toda possível origem. Como sinaliza Emir Rodríguez Monegal (1979), trata-se de uma integração cultural que não pode ser vista como submissão aos modelos ocidentais, ou como mera corrupção de algum original sagrado. Não é possível, pois, uma reflexão acerca da formação do teatro brasileiro senão situada 
na relação com o movimento paródico nas artes cênicas. Para além dos manuais e das viagens de estudo em Portugal, a paródia exerce um papel que se mostra fundamental na formação dos autores, atores e demais artistas do teatro brasileiro.

\section{Do teatro da história do teatro}

A paródia possui a instigante particularidade de conter a crítica no próprio ato artístico. Opera por uma abordagem criativa da tradição ou do passado em um processo de apropriação e recontextualização que instaura uma distância crítica. Para marcar a diferença, e não a semelhança. Trata-se menos de um gênero que de um gesto, que institui um ponto privilegiado de observação. Como um espelho falso, permite um olhar circular para o objeto, conforme se iluminem criação e/ou crítica.

Entretanto, o caráter da paródia não é exclusivamente crítico. Pode funcionar como uma "combinação de homenagem respeitosa de 'torcer o nariz' irônico" (HUTCHEON, 1985, p. 49), já que "a sua transgressão é sempre autorizada. Ao imitar, mesmo com diferença crítica, a paródia reforça" (HUTCHEON, 1985, p. 39). Com isso, adquire um sentido histórico, que é o de carregar os traços do desejo artístico daqueles que a produzem, ainda que de viés; no nosso caso, de desvelar o teatro que se quer. A um só tempo, portanto, caracteriza-se como teatro e história do teatro.

A prática parodística se transmutará, no século XX, com o projeto modernista. No teatro, essa mutação aparecerá primeiro na dramaturgia, com Oswald de Andrade, na década de 1930, sem que se reflita imediatamente na cena, o que se dará somente em 1967 com a montagem de O rei da vela por José Celso Martinez Corrêa. Com Oswald e José Celso, a prática paródica supera o foco temático. Ao romper com a dramaturgia tradicional, apropria-se de formas teatrais e não teatrais - circenses, literárias, revisteiras, operísticas - na construção de uma obra híbrida, polifônica, aberta, que parodia a própria ideia de teatro. Como "bárbaros alexandrinos, aprovisionados de bibliotecas caóticas e de fichários labirínticos", no dizer de Haroldo de Campos, esses artistas fundam sua criação em um novo cogito, tal como enunciado por José Celso: "Esculhambo, logo existo!" (CORRÊA, 2003, p. 22). A paródia, a partir 
de então, formula novos sentidos de brasilidade, sob uma perspectiva plural, que pulveriza a dicotomia centro-periferia.

Descentrada, marginal, paralela, a paródia, no âmbito do teatro brasileiro, desmantela divisas, ao imbricar canto e contracanto, criação e crítica, ideia e simulacro. Enfraquece valores eurocêntricos, a que sobrepõe um caleidoscópio de múltiplos espaços-tempos, de múltiplas vozes em coexistência. Assume o próprio gesto de troca como valor, livrando-se da entronização da ideia de identidade, bem como da nostalgia (ou ilusão) romântica da originalidade.

\section{Referências bibliográficas}

AZEVEDO, A. Abel, Helena. 1877. Disponível em: <http://www.literaturabrasileira. ufsc.br/_documents/0006-02983.html>. Acesso em: 18 fev. 2015.

CAMPOS, H. Apresentação. In: ANDRADE, O. Oswald de Andrade: trechos escoIhidos por Haroldo de Campos. Rio de Janeiro: Agir, 1967. (Coleção Nossos clássicos, 91)

Da razão antropofágica: diálogo e diferença na cultura brasileira. Boletim bibliográfico. Biblioteca Mário de Andrade, Secretaria Municipal de Cultura de São Paulo, v. 44, n. 1-4, p. 107-127, jan./dez. 1983.

CORRÊA, J. C. M. O rei da vela: manifesto do oficina. In: ANDRADE, O. O Rei da Vela. São Paulo: Globo, 2003. (Obras completas de Oswald de Andrade.)

FARIA, J. R. (Dir.). História do teatro brasileiro, volume 1: das origens ao teatro profissional da primeira metade do século XX. São Paulo: Perspectiva; SESC-SP, 2012.

HUTCHEON, L. Uma teoria da paródia: ensinamentos das formas de arte do século XX. Trad. Tereza Louro Pérez. Lisboa: Edições 70, 1985.

METZLER, M. Teatro da natureza: história e ideias. São Paulo: Perspectiva, 2006.

Alda Garrido: as mil faces de uma atriz popular brasileira. Tese (Doutorado em Artes Cênicas) - Universidade Federal do Estado do Rio de Janeiro, Rio de Janeiro, 2011.

MONEGAL, E. R. Carnaval / Antropofagia / Parodia. Revista Iberoamericana, Pittsburgh, n. 108-109, 1979. Disponível em: <http://revista-iberoamericana.pitt.edu/ ojs/index.php/lberoamericana/article/view/3388/3567>. Acesso em: 12 fev. 2015. doi: http://dx.doi.org/10.5195/reviberoamer.1979.3388.

OFFENBACH, J.; MEILHAC, H.; HALÉVY, L. La belle Hélène. 1864. Disponível em: <http://fr.wikisource.org/w/index.php?title=La_Belle_H\%C3\%A9l\%C3\%A8ne\&printable=yes>. Acesso em: 18 fev. 2015. 
OFFENBACH, J.; CRÉMIEUX, H. Orphée aux Enfers. 1858. Disponível em: <http:// fr.wikisource.org/w/index.php?title=Orph\%C3\%A9e_aux_Enfers\&printable=yes $>$. Acesso em: 18 fev. 2015.

PAIVA, S. C. Viva o Rebolado!: Vida e morte do teatro de revista brasileiro. Rio de Janeiro: Nova Fronteira, 1991.

PINTO, A. S.; RABETTI, M. L. Cenas passadas: as operetas Jurity (1919) e Orphée aux Enfers (1865). In: VIII Congresso da Associação Brasileira de Pesquisa e Pós-Graduação em Artes Cênicas, Belo Horizonte, UFMG, 2014. Anais do VIII Congresso da ABRACE. Belo Horizonte: ABRACE, 2014. Disponível em: <http:// portalabrace.org/1/index.php/encontros/viii-congresso-da-abrace/gt-historia-das -artes-do-espetaculo/2209-copy-of-cenas-passadas-danca-e-musica-nas-operetas-jurity-1919-e-orphee-aux-enfers-1865-548>. Acesso em: 14 fev. 2015.

TAVARES, E. F. Otelo, o Mouro de Veneza, de Shakespeare: crítica e tradução literária. 2007. Dissertação (Mestrado). Universidade Federal de Santa Maria, Santa Maria, Rio Grande do Sul. Disponível em: <http://www.dbd.puc-rio.br/shakespeare/pdfs/dissertacaoEneiasTavares.pdf>. Acesso em: 27 mar. 2015.

VASQUES, F. C. Orfeu na Roça. In: FERREIRA, P. O ator Vasques. Rio de Janeiro: Serviço Nacional de Teatro, 1979.

VENEZIANO, N. O teatro de revista no Brasil: dramaturgia e convenções. Campinas: Pontes; Editora da Unicamp, 1991.

Recebido em 15/03/2015

Aprovado em 23/05/2015

Publicado em 30/06/2015 